\title{
Endoscopic submucosal dissection versus transanal local excision for rectal carcinoid: a comparative study
}

\author{
Fei-hu Yan ${ }^{1,2}$, Zheng Lou', Shi-jie Hư ${ }^{3}$, Xiao-dong Xu', Hao Wang ${ }^{1}$, Han-tao Wang ${ }^{1}$, Rong-gui Meng ${ }^{1}$,
} Chuan-gang $\mathrm{Fu}^{1}$, Wei Zhang ${ }^{1}$, Jian $\mathrm{He}^{1}$ and En-da $\mathrm{Yu}^{1 *}$

\begin{abstract}
Aim: The aim of this study is to compare the short-term clinical outcomes between endoscopic submucosal dissection and transanal local excision for rectal carcinoid tumors.

Methods: Between 2007 and 2012, 31 patients with rectal carcinoid underwent endoscopic submucosal dissection at our hospital. They were compared with a matched cohort of 23 patients who underwent transanal local excision for rectal carcinoid between 2007 and 2012. Short-term clinical outcomes including surgical parameters, postoperative recovery, and oncologic outcomes were compared between the two groups.

Results: The mean size of tumors was significantly bigger in the transanal local excision group $(0.8 \pm 0.2$ versus $1.1 \pm 0.5 \mathrm{~cm} ; P=0.018$ ). En bloc resection was achieved for 30 patients (97 \%) in the endoscopic submucosal dissection group and all the patients in the transanal local excision group. The operation time was longer in the transanal local excision than that in the endoscopic submucosal dissection group ( $40.0 \pm 22.7$ min versus $12.2 \pm 5.3 \mathrm{~min} ; P<0.001)$. Complications in the transanal local excision group were five cases of acute retention of urine. There was no local recurrence or distant metastasis in either group during the follow-up period.

Conclusion: For the treatment of rectal carcinoid tumors with diameter $<1 \mathrm{~cm}$, endoscopic submucosal dissection has better short-term clinical outcomes than transanal local excision in terms of faster recovery and possibly a lower morbidity rate. Transanal local excision may be the first therapeutic choice of scar-embedded rectal carcinoid tumors.
\end{abstract}

Keywords: Rectal carcinoid, Endoscopic submucosal dissection, Transanal local excision

\section{What does this paper add to the literature statement?}

In this work, we compare the short-term clinical outcomes between endoscopic submucosal dissection (ESD) and transanal local excision (TALE) for rectal carcinoid tumors, so as to help surgeons decide which method should be chosen for these patients.

\section{Background}

Rectal carcinoid tumors account for $18.5 \%$ of all carcinoid tumors. Although these tumors represent only $1.3 \%$

\footnotetext{
* Correspondence: fei1989hu@163.com

'Department of Colorectal Surgery, Changhai Hospital, Second Military

Medical University, Changhai Road 168\#, Shanghai, China

Full list of author information is available at the end of the article
}

of all rectal neoplasms, their incidence is drastically increasing $[1,2]$. These tumors can show a broad range of clinical behavior, from benign and asymptomatic to disseminated and metastatic [3]. Because rectal carcinoid tumors often present as small and localized tumors that rarely recur after resection, rectal carcinoid tumors have the best prognosis among all carcinoid tumors with a 5year survival rate at $88.3 \%$, and thus have usually been managed with local excision [4-6].

For rectal carcinoid tumors not amenable to conventional colonoscopic removal, the alternative treatment option is TALE procedure. This local procedure has proved to be safe and effective in the treatment of low rectal lesions. However, TALE approach must be performed with the patient under anesthesia, such as spinal anesthesia, 
general endotracheal anesthesia (GETA), and IV sedation + local depending on tumor location and size, especially the characteristics and comorbidities of patients.

ESD is a novel colonoscopic method that enables en bloc resection for colorectal lesions. It can be performed with patients without anesthesia. The ESD approach has a reported perforation rate of 2 to $10 \%$, an en bloc resection rate of 80 to $90 \%$, and a short-term recurrence rate for colorectal ESD of 0 to $2.1 \%$ [7].

In the traditional sense, the indications of TALE for rectal carcinoid tumors are as follows: (1) tumor located less than $7 \mathrm{~cm}$ to anal edge, (2) tumor size accounted less than $1 / 3$ lumen diameter, (3) tumor node metastasis (TNM) staged earlier than T1. Except the above situation, choose surgical oncologic resection. Despite a growing understanding of the clinical effectiveness of local excision for small rectal carcinoid tumors, there is still controversy concerning the best surgical choice for rectal carcinoid tumors with different diameters [8]. The aim of this study is to report our experiences of adopting two different local excision procedures according to tumor diameter. To our knowledge, there is no report about the surgical strategies and results of ESD and TALE for rectal carcinoid tumors.

\section{Methods}

\section{Patients and study design}

Between October 2007 and December 2012, 78 patients with rectal carcinoid were admitted to Changhai Hospital. We included 54 patients in our study (31 patients underwent ESD, 23 patients underwent TALE). The inclusion criteria for TALE and ESD based upon tumor size, location, and TNM stage: (1) tumor located less than $7 \mathrm{~cm}$ to anal edge, (2) tumor size accounted less than 1/3 lumen diameter, (3) TNM staged earlier than T1. Then, we excluded 24 patients who underwent surgical oncologic resection. The clinical data of patients with rectal carcinoid who underwent either ESD or TALE were retrospectively reviewed. In this study, we enrolled patients with rectal carcinoid tumors that did not show regional lymph node enlargement on computed tomography (CT) scanning or endorectal ultrasonography (EUS) as previously reported [9]. Patients underwent local excision using ESD or TALE. All specimens were referred to pathologists and examined microscopically for tumor size, depth of invasion, and resection margin status. The patients' characteristics, operative details, pathological results, and short-term outcomes were recorded. Six experienced, qualified surgeons and endoscopists (En-da Yu, 30 years experience; Zheng Lou, 12 years experience; Rong-gui Meng, 32 years experience; Wei Zhang, 25 years experience; Lian-jie Liu, 26 years experience; Li-qiang Hao, 19 years experience, et al.) performed the procedures (TALE and ESD).

Informed consent was obtained from all patients. The study protocol conformed to the ethical guidelines of the
Helsinki Declaration. The ethical review has been approved by The Ethics Committee of Changhai Hospital.

\section{Data and materials \\ TALE}

In our study, all TALE procedures were performed with the patient under spinal anesthesia, lithotomy position, or clasp knife position. Anal retractors were first introduced into the anal canal to maintain exposure. Normal saline was injected into the submucosal plane with an injector syringe to create a visible submucosal cushion for elevation of the lesion. The tumor then was excised with electrocautery or an ultrasonic knife (Johnson) under direct vision, performed in a submucosal resection, then the wound was closed with absorbable sutures (Johnson). But, one patient underwent additional surgery (TALE) after ESD because the ESD specimen showed a positive resection margin, in a full thickness fashion.

\section{ESD}

In our center, we use a two-person approach to colonoscopy. ESD was performed using a conventional endoscope (CF-H260, Olympus, Tokyo, Japan). A mixture of glycerin and fructose, normal saline, adrenaline, and methylene blue was injected into the submucosal plane with a submucosal injection needle (Alton) to create a visible submucosal cushion for elevation of the lesion. Mucosal incision and submucosal dissection were performed using the needle knife or insulated tip knife (Olympus Endoscopy Medical System, Tokyo, Japan) depending on the individual endoscopists' preference. All procedures were performed without anesthesia. The patients undergoing ESD did not receive any kind of IV sedation.

\section{Outcome measurements}

Short-term clinical outcomes included operative time, morbidity rate, time to ambulation, and hospital stay. Morbidity was defined as any complication that required reintervention or resulted in prolonged hospital stay. Bleeding was defined as any bleeding episode during or after the operation that required blood transfusion. Perforation was either identified during the operation or diagnosed when free intraperitoneal gas was found on abdominal imaging after the operation. Acute retention of urine was defined as failure to void within $24 \mathrm{~h}$ after the operation. Other operative details including the operative time and the en bloc resection rate also were compared between the two groups.

\section{Methods of postoperative surveillance}

We mainly used medical records and nursing records to get initial postoperative information; we also conformed these information by telephone follow-up and got more follow-up data. 


\section{Statistical analysis}

Continuous variables were presented as mean (standard deviation), and dichotomous variables were presented as number and percentage values. Patients with different procedures were compared in regard to age, sex, and pathologic tumor characteristics with Fisher exact test, chi-square test, or independent $t$ test, as appropriate. All analyses were performed with SPSS version 17 statistical software package (SPSS, Inc., Chicago, IL).

\section{Results}

The baseline characteristics of the two groups were shown in Table 1. The two groups did not differ in terms of age, sex, or distance from anal verge. The mean size of tumors was significantly bigger in the TALE group $(0.8 \pm 0.2$ versus $1.1 \pm 0.5 \mathrm{~cm} ; P=0.018)$. En bloc resection was achieved for 30 patients (97\%) in the ESD group and all the patients in the TALE group.

Operative time was longer in the TALE than in the ESD group $(40.0 \pm 22.7 \mathrm{~min}$ versus $12.2 \pm 5.3 \mathrm{~min} ; P<0.001)$. Complications in the TALE group were five cases of AROU. There were no bleeding or perforation cases in either group. Table 2 summarizes procedure-related parameters.

Follow-up data was available in 24 patients in the ESD group because seven patients were not due for follow-up at the time of analysis. One patient underwent additional surgery (TALE) after ESD because the ESD specimen showed positive resection margin. Follow-up data was analyzed in 18 patients in the TALE group. The median follow-up period was 16.4 months (range 8-31 months) in the ESD group and 28.4 months (range 8-68 months) in the TALE group. The median number of follow-up colonoscopies was 1.9 times (range 1-4 times) in the ESD group and 2.5 times (range 1-5 times) in the TALE group. There was no local recurrence or distant metastasis in any patients in either group during the follow-up period.

Table 1 Demographic data and tumor characteristics for the TALE and ESD groups

\begin{tabular}{llll}
\hline & TALE $(n=23)$ & ESD $(n=31)$ & $p$ value \\
\hline Mean age (years) & $47.9 \pm 11.7$ & $52.2 \pm 10.2$ & 0.159 \\
Sex (male/female) & $14 / 9$ & $22 / 9$ & 0.436 \\
Tumor size (cm) & $1.1 \pm 0.5$ & $0.8 \pm 0.2$ & 0.018 \\
Distance from anal verge (cm) & $5.4 \pm 1.5$ & $5.9 \pm 2.3$ & 0.435 \\
En bloc resection: $n(\%)$ & $23(100 \%)$ & $30(97 \%)$ & 1.0 \\
Operation time & $40.0 \pm 22.7$ & $12.2 \pm 5.3$ & $<0.001$ \\
Muscular invasion & 0 & 0 & $/$ \\
Lymphovascular invasion & 0 & 0 & $/$ \\
\hline
\end{tabular}

Table 2 Short-term postoperative complications

\begin{tabular}{lllll}
\hline Procedure & AROU & Anus ache & Bleeding & Perforation \\
\hline TALE & 5 & 16 & 0 & 0 \\
ESD & 0 & 3 & 0 & 0 \\
$p$ value & 0.024 & $<0.001$ & $/$ & $/$ \\
\hline
\end{tabular}

\section{Discussion}

Rectal carcinoid tumor is a rare condition accounting for only $1.3 \%$ of the overall rectal tumor cases $[10,11]$. Tumor size has been a known prognostic factor for rectal carcinoid tumors. ESD, TALE, and radical resection have been performed as treatments of rectal carcinoid tumor. However, it is currently difficult to decide between treatments such as local excision and radical surgery, especially for tumors that are $>1$ to $\leq 2 \mathrm{~cm}$ in diameter. It appears that small rectal carcinoids $<1 \mathrm{~cm}$ in size can be safely managed by local excision. For tumors $>1$ to $\leq 2 \mathrm{~cm}$, local excision is usually recommended, but radical surgery should be considered if there is evidence of lymph node metastasis [12]. The preoperative radiological evaluation of lymph node metastasis was critical. Pelvic imaging evaluation such as CT or endorectal ultrasound was made, and no enlarged lymph nodes were found in our patients before surgery.

ESD and TALE are performed for local excision of rectal carcinoids in daily clinical work. Which is the best method for the local resection of rectal carcinoids? Son et al. reported pathologically determined completeresection (P-CR) rates for small rectal carcinoid tumors excised by using several methods. The P-CR rates were $30.9,72.0$, and $81.8 \%$ for a conventional endoscopic polypectomy, ESD, and TALE [13]. TALE is a traditional procedure for treating lower rectal tumors and provides deeper vertical resection margin. Kim et al. [14] described the complete-resection rate for transanal surgery as over $97 \%$. Recently Son et al. reported that the pathologically complete-resection rates were $30.9,72.0$, and $81.8 \%$ for conventional polypectomy, advanced endoscopic techniques, and surgical local excision, respectively. Pathologically complete-resection of small rectal carcinoid tumors was more likely to be achieved when using surgical local excision [14]. Ono et al. [15] described results obtained with 14 rectal carcinoid tumors treated by ESD between 1999 and 2002. All tumors were completely resected, and no recurrence was noted at a median follow-up of 10.5 months. In our study, the mean tumor size was $1.1 \pm 0.5 \mathrm{~cm}$ and $0.8 \pm 0.2 \mathrm{~cm}$ in TALE and ESD group, respectively. All lesions were confined to the submucosal layer. The pathologically completeresection rates were 97 and $100 \%$ for ESD and TALE, respectively. The results suggested that pathologically complete resection of rectal carcinoid tumors can be 
achieved when using proper procedure according to the tumor size.

However, TALE must be also considered to be more invasive because of the risk associated with the use of anesthesia [14]. Spinal anesthesia is a risk factor for acute retention of urine (AROU). In fact, anal dilation or retraction because of operation may cause anal pain and also may result in AROU. These factors explain why the TALE group had a significantly higher incidence of AROU. On the other hand, ESD is performed without anesthesia, and there is no need to dilate the anal sphincter. This may account for the lower morbidity rate and shorter operative time in the ESD group.

But for a local recurrence case, TALE may be more appropriate. ESD was performed after a mixture of glycerin and fructose, normal saline, adrenaline, and methylene blue was injected into the submucosal layer in order to achieve en bloc resection and avoid perforation. However, the lesion cannot be lifted after injection because of the existence of fibrosis in the submucosal layer in the case of local recurrence. The cut and the dissection steps that use cutting devices may be technically difficult. Fujishiro et al. reported that endoscopic en bloc resection was not achieved in some colorectal tumors because of fibrosis which prevented a sufficient submucosal fluid cushion in the submucosal layer [16]. In the TALE group, one patient had a reoperation because of positive resection margin with ESD. By TALE procedure, the tumor was removed with R0 resection. From our opinion, TALE may be a safe and effective method in the treatment of scar embedded lesion.

This study had some limitations. First, this was a retrospective study. We were unable to fully evaluate possible confounders, owing to the retrospective nature of this study. The second limitation of this study was that further follow-up studies are required to more accurately define the long-term outcomes of TALE and ESD. The third limitation of this study was the limited presented data and the number of patients enrolled. It is because the disease incidence is low that there is a difficulty of achieving an adequate number of cases for comparative analysis. Best results should be achieved with work with more patients and preferably a multicenter.

\section{Conclusion}

In conclusion, for the treatment of rectal carcinoid tumors with diameter $<1 \mathrm{~cm}$, ESD has better short-term clinical outcomes than TALE in terms of faster recovery and possibly a lower morbidity rate. TALE may be the first therapeutic choice of scar embedded rectal carcinoid tumors. Prospective studies with larger samples are needed to validate the benefits of TALE.

\section{Abbreviations}

AROU, acute retention of urine; P-CR, pathologically determined complete resection; $C T$, computed tomography; EUS, endorectal ultrasonography; ESD, endoscopic submucosal dissection; TALE, transanal local excision; GETA, general endotracheal anesthesia; TNM, tumor node metastasis.

\section{Acknowledgements \\ None. \\ Funding \\ This work was supported by the foundation from Changhai Hospital 1255 project (No. CH125542500), Changhai Hospital, Shanghai, Republic of China and Key areas of science and technology commission of Shanghai basic research project (No.13JC1407200), Shanghai, Republic of China.}

\section{Availability of data and materials}

The dataset supporting the conclusions of this article is included within the article (line 1-23, Page 6) and its additional file.

\section{Authors' contributions}

FHY, ZL, and SJH contributed equally to this work and are considered co-first authors. ZL, EDY, RGM, WZ, and CGF performed the majority of treatment;

$\mathrm{ZL}, \mathrm{FHY}, \mathrm{SJH}, J \mathrm{H}$, and XDX were involved in editing the manuscript; EDY, WZ, XDX, HW, HTW, and CGF co-ordinated and provided the collection of all the clinical data in addition to providing financial support for this work; ZL, FHY, $\mathrm{SJH}$, and EDY designed the study and wrote the manuscript. All authors read and approved the final manuscript.

\section{Competing interests}

The authors declare that they have no competing interests.

\section{Consent for publication}

Not applicable.

\section{Ethics approval and consent to participate}

Written informed consent was obtained from all of these patients for the acceptance of ESD or TALE and for publication of this manuscript. A copy of the written consent is available for review by the Editor-in-Chief of this journal if necessary. The ethical review has been approved by The Ethics Committee of Changhai Hospital (no. CHEC2013-143).

\section{Author details}

${ }^{1}$ Department of Colorectal Surgery, Changhai Hospital, Second Military Medical University, Changhai Road 168\#, Shanghai, China. ${ }^{2}$ Department of General Surgery, 413 Hospital, Zhoushan, China. ${ }^{3}$ Department of Colorectal Surgery, Jianmin Colorectal Disease Hospital, Yong gang South Road 225\#, Ningbo, China.

Received: 20 January 2016 Accepted: 15 June 2016

Published online: 21 June 2016

\section{References}

1. Scherubl H. Rectal carcinoids are on the rise: early detection by screening endoscopy. Endoscopy. 2009;41(2):162-5.

2. Taghavi S, Jayarajan SN, Powers BD, Davey A, Willis Al. Examining rectal carcinoids in the era of screening colonoscopy: a surveillance, epidemiology, and end results analysis. Dis Colon Rectum. 2013;56(8):952-9.

3. Wang AY, Ahmad NA. Rectal carcinoids. Curr Opin Gastroenterol. 2006;22(5): 529-35.

4. Kumar AS, Sidani SM, Kolli K, Stahl TJ, Ayscue JM, Fitzgerald JF, et al. Transanal endoscopic microsurgery for rectal carcinoids: the largest reported United States experience. Colorectal Dis. 2012;14(5):562-6.

5. Hamada Y, Tanaka K, Tano S, Katsurahara M, Kosaka R, Noda T, et al. Usefulness of endoscopic submucosal dissection for the treatment of rectal carcinoid tumors. Eur J Gastroenterol Hepatol. 2012;24(7):770-4.

6. Niimi K, Goto O, Fujishiro M, Kodashima S, Ono S, Mochizuki S, et al. Endoscopic mucosal resection with a ligation device or endoscopic submucosal dissection for rectal carcinoid tumors: an analysis of 24 consecutive cases. Dig Endosc. 2012;24(6):443-7. 
7. Hon SS, Ng SS, Chiu PW, Chan FK, Ng EK, Li JC, et al. Endoscopic submucosal dissection versus local excision for early rectal neoplasms: a comparative study. Surg Endosc. 2011;25(12):3923-7.

8. Zhao ZF, Zhang N, Ma SR, Yang Z, Han X, Zhao YF, et al. A comparative study on endoscopy treatment in rectal carcinoid tumors. Surg Laparosc Endosc Percutan Tech. 2012;22(3):260-3.

9. Park HW, Byeon JS, Park YS, Yang DH, Yoon SM, Kim KJ, et al. Endoscopic submucosal dissection for treatment of rectal carcinoid tumors. Gastrointest Endosc. 2010;72(1):143-9.

10. Godwin 2nd JD. Carcinoid tumors. An analysis of 2,837 cases. Cancer. 1975; 36(2):560-9.

11. Teleky B, Herbst F, Langle F, Neuhold N, Niederle B. The prognosis of rectal carcinoid tumours. Int J Colorectal Dis. 1992;7(1):11-4.

12. Yoon SN, Yu CS, Shin US, Kim CW, Lim SB, Kim JC. Clinicopathological characteristics of rectal carcinoids. Int J Colorectal Dis. 2010;25(9):1087-92.

13. Son HJ, Sohn DK, Hong CW, Han KS, Kim BC, Park JW, et al. Factors associated with complete local excision of small rectal carcinoid tumor. Int J Colorectal Dis. 2013;28(1):57-61.

14. Kim HR, Lee WY, Jung KU, Chung HJ, Kim CJ, Yun HR, et al. Transanal endoscopic microsurgery for the treatment of well-differentiated rectal neuroendocrine tumors. J Korean Soc Coloproctol. 2012;28(4):201-4.

15. Ono A, Fujii T, Saito Y, Matsuda T, Lee DT, Gotoda T, et al. Endoscopic submucosal resection of rectal carcinoid tumors with a ligation device. Gastrointest Endosc. 2003;57(4):583-7.

16. Fujishiro M, Yahagi N, Nakamura M, Kakushima N, Kodashima S, Ono S, Kobayashi K, Hashimoto T, Yamamichi N, Tateishi A, Shimizu Y, Oka M, Ogura K, Kawabe T, Ichinose M, Omata M. Successful outcomes of a novel endoscopic treatment for Gl tumors: endoscopic submucosal dissection with a mixture of high-molecular-weight hyaluronic acid, glycerin, and sugar. Gastrointest Endosc. 2006;63(2):243-9.

\section{Submit your next manuscript to BioMed Central and we will help you at every step:}

- We accept pre-submission inquiries

- Our selector tool helps you to find the most relevant journal

- We provide round the clock customer support

- Convenient online submission

- Thorough peer review

- Inclusion in PubMed and all major indexing services

- Maximum visibility for your research

Submit your manuscript at www.biomedcentral.com/submit

C Biomed Central 